\title{
La participación ciudadana: un marco conceptual
}

\author{
Luis Serra Vázquez \\ Investigador. Correo electrónico: luishectorserra@yahoo.com.ar
}

Recibido: julio de 2008 / Aceptado: octubre de 2008

ESTE DOCUMENTO PRESENTA UN PANORAMA RESUMIDO DE LOS PRINCIPALES abordajes teóricos del fenómeno de la participación ciudadana, iniciando con una conceptualizacion de la "ciudadanía" y de la "participación" desde distintas miradas disciplinares.

En una segunda parte se aborda el debate sobre los factores condicionantes de la participación ciudadana desde distintos criterios analíticos, facilitando así la focalización de acciones de construcción de ciudadanía y la explicación de experiencias de participación ciudadana. La tercera sección presenta las principales tipologías elaboradas en torno a la participación, las cuales ofrecen variables e indicadores para analizar y valorar diferentes dinámicas y organizaciones ciudadanas.

Por último se exponen los principales resultados de este breve trabajo conceptual de carácter didáctico, que pretende contribuir a fortalecer las investigaciones o las intervenciones que se realicen sobre distintos aspectos y sujetos de la participación ciudadana en Nicaragua.

Palabras clave: participación ciudadana / concepto / tipologías

\section{Pertinencia del tema}

El concepto de participación ciudadana (PC) es ampliamente utilizado con distintos sentidos por parte de diversos agentes sociales tales como partidos políticos, organizaciones sociales, medios de comunicación, instituciones de desarrollo, centros educativos e institutos de investigación. Esta diversidad de acepciones y usos conlleva a una ambigüedad e imprecisión del concepto de participación ciudadana que dificulta identificar el fenómeno, poder estudiarlo científicamente y plantear medidas fundamentadas para promoverla y así contribuir a la democratización en nuestros países.

Sin duda, la participación ciudadana en los asuntos públicos que afectan sus intereses individuales o sociales es un componente clave de una "gobernabilidad democrática" o "buen gobierno". Su ejercicio eficiente y oportuno otorga a las políticas públicas que 
han sido consensuadas con la ciudadanía la oportunidad de enriquecerse con sus aportes, además de dotarlas de la legitimidad que facilita su validez y su cumplimiento efectivo.

Asimismo, la participación ciudadana en el monitoreo de políticas y uso de recursos públicos contribuye a la transparencia y a la eficiencia de la gestión publica, es decir, mitiga la corrupción y el burocratismo en instituciones estatales. Por otro lado, se ha señalado que la participación ciudadana contribuye a la sostenibilidad de las políticas públicas, superando la coyuntura temporal de una administración de gobierno para constituirse en políticas de Estado a mediano y largo plazo, fortaleciendo el estado de derecho en un país determinado.

En las últimas décadas ha resurgido el interés político y académico por el concepto de participación ciudadana debido a varios procesos interrelacionados. Por un lado observamos el rol protagónico que han jugado las organizaciones civiles y los movimientos sociales en el cambio de regímenes políticos autoritarios en distintos países, como en Europa del Este o en América Latina, así como en cuestionar el actual modelo de globalización excluyente y antiecológico. En estas regiones, el establecimiento de regímenes democráticos representativos que permiten la libre expresión y organización, ha facilitado una multiplicación de demandas ciudadanas y de grupos de interés. En cambio, los partidos políticos han sufrido una crisis de representatividad por su escasa capacidad de canalizar las demandas ciudadanas y de superar intereses personales de poder (Hengstenberg et al., 1999).

La crisis del estado de bienestar, el auge del neoliberalismo y el creciente poder del FMI -basado en el Consenso de Washington- han facilitado el recorte de las funciones y recursos del estado nación, dejando a las fuerzas del mercado y a los ciudadanos la resolución de las necesidades básicas de la población. En este contexto ha resurgido el debate sobre la "ciudadanía social”, es decir, sobre los derechos sociales que había conquistado la población de los países del Norte y del Este, y que pretenden alcanzar los pueblos del Sur. Para los neoliberales se trataba de superar la dependencia ciudadana del Estado, que regalaba los servicios sociales, y promover una ciudadanía responsable y autosuficiente. Desde una perspectiva opuesta, se argumentaba que estas políticas aumentaban la desigualdad, la pobreza y la falta de condiciones básicas para el ejercicio de una ciudadanía real (Pérez Ledesma, 2004).

La creciente insatisfacción en América Latina con una ciudadanía que se limita a la emisión del voto por candidatos predeterminados que luego olvidan sus promesas y se lucran de fondos públicos, ha propiciado el debate entre la democracia representativa -basada en la elección de gobernantes propuestos por partidos políticos mediante elecciones periódicas y libres de ciudadanos que gozan de derechos civiles y políticos- y la democracia participativa - que enfatiza la gestión permanente y directa de la ciudadanía en las decisiones que afectan su vida social y en el control de la gestión pública. Paralelamente, se discute sobre los límites de la democracia política representativa en una sociedad de amplias desigualdades socioeconómicas. Así ha surgido la demanda de ciudadanos que para ejercer sus derechos exigen de una expansión de la democracia al ámbito económico, social y cultural, es decir, una ciudadanía con derechos plenos en las distintas dimensiones de la vida social (Sojo, 2002). 
El reconocimiento jurídico del derecho ciudadano a participar en los asuntos públicos de un país es un elemento clave de un sistema político democrático y un derecho consignado en diversos convenios internacionales, tal como la Declaración Universal de Derechos Humanos que establece que: "Toda persona tiene derecho a participar en el gobierno de su país, directamente o por medio de sus representantes libremente escogidos" (ONU, 1948:Arto.21). Este derecho ha sido reconocido en los marcos jurídicos de casi todos los países del mundo, sin embargo se observa una brecha considerable entre el "deber ser" jurídico y el ejercicio real de estos derechos ciudadanos en muchas naciones.

Por razones prácticas, el alto número de ciudadanos que tienen los estados contemporáneos y su dispersión geográfica, impide una participación directa más allá del ámbito local. Por ello se han establecido mecanismos de participación indirecta de los ciudadanos en asuntos políticos a través de representantes de los partidos políticos o de organizaciones civiles. La combinación de ambas formas de participación -directa y representativa- es un rasgo peculiar de constituciones avanzadas como la nicaragüense, donde se establece que nuestro sistema político es una república democrática, participativa y representativa.

En este siglo XXI diversos actores sociales latinoamericanos han puesto en agenda la "construcción de ciudadanía" como una tarea fundamental para potenciar las capacidades humanas y sociales de incidir en la gestión pública a fin de responder a sus demandas de superación de la pobreza y de desarrollo sostenible. Frente a un preocupante proceso de "desciudadanizacion" fomentado por la globalización, Aquin señala desde su experiencia en Trabajo Social, que "los valores y el ejercicio de la ciudadanía mejoran las condiciones de conformación de una opinión pública crítica, al mismo tiempo que aumentan la capacidad de demanda de la sociedad en materia de elaboración de políticas y decisiones públicas" (2003:8).

La relevancia del debate sobre ciudadanía para abordar la compleja problemática sociopolítica de América Latina ha sido señalada por Tourain: "El tema de la ciudadanía significa la construcción libre y voluntaria de una organización social que combina unidad de la ley con la diversidad de los intereses y el respeto a los derechos fundamentales" (citado en Sojo, 2002:32). En el fondo, la participación ciudadana aborda el espinoso tema de la distribución de recursos materiales y políticos. Se trata de democratizar el poder político incluyendo a todos los sectores sociales y se apunta a compartir los recursos que permitan condiciones de vida dignas para todos/as en una sociedad.

En Nicaragua, el tema de la participación ciudadana ha concitado el interés de políticos, académicos y líderes civiles, dado que constituye un elemento clave para la democratización del sistema político y para un desarrollo sostenible e inclusivo. En 2007 ha resurgido el debate sobre la participación ciudadana a raíz de la política del actual gobierno de promover la "democracia directa" a través de un sistema nacional de Consejos de Poder Ciudadanos subordinados al Poder Ejecutivo. En este contexto, es necesario analizar los fundamentos teóricos del concepto y la práctica de la participación ciudadana en nuestro país, así como realizar estudios científicos sobre sus manifestaciones a nivel local y nacional, tratando de identificar los factores condicionantes y de extraer lecciones para su fortalecimiento, tal como plantea la Red Nicaragüense por la Democracia y el Desarrollo Local junto con el Observatorio de Participación Ciudadana. 


\section{Ciudadanía: distintas perspectivas conceptuales}

Desde una perspectiva histórica, recordemos que en la Grecia clásica los ciudadanos eran las personas miembros de una "polis" o ciudad-estado que gozaban de plenos derechos de participar en el gobierno y en las decisiones sobre asuntos públicos, a diferencia de los esclavos, los plebeyos y los extranjeros. La ciudadanía era una comunidad política de un pequeño grupo de personas que ostentaban iguales derechos políticos y civiles. Al igual que en la Roma antigua, la ciudadanía se adquiría por nacimiento de padres griegos o romanos que pertenecían a una familia extensa ("genos" o "gens"). El estatus de ciudadano daba derecho a participar en decisiones públicas, elección de autoridades o ejercer cargos de gobierno o justicia. Por otro lado, imponía deberes como pagar impuestos y hacer servicio militar.

La ampliación del concepto y la práctica de ciudadanía ha sido un largo proceso histórico -impulsado por los grupos sociales excluidos de las decisiones políticas- que continúa hasta el presente siglo con distintos matices según los contextos nacionales. En Europa del medioevo tardío (siglos XIII-V) fueron las emergentes burguesías comerciantes y financieras asentadas en las ciudades quienes se enfrentaron al Estado Absolutista, controlado por la nobleza terrateniente y la Iglesia Católica, para obtener el derecho a la ciudadanía fundamentada en las tesis de cientistas, filósofos y artistas del Renacimiento y la Ilustración. Las revoluciones ocurridas en Estados Unidos (1776) y Francia (1789) proclamaron que todos los seres humanos nacen libres y con derechos iguales: la libertad, la propiedad, la seguridad, la elección y remoción de gobiernos.

Sin embargo, en la práctica se mantuvieron restricciones fuertes a la ciudadanía para las mujeres, los pobres, los negros y los indígenas hasta mediados o fines del siglo XX, cuando triunfaron en la mayoría de los países las luchas de estos grupos sociales para lograr su condición de plena ciudadanía y mejorar sus condiciones de vida. En definitiva, el proceso histórico de ampliación y profundización de la ciudadanía alimenta el desarrollo de la democracia como sistema político. No obstante, las experiencias durante el siglo XX de dictaduras en países del norte y del sur, muestran que los avances en la ciudadanía democrática pueden ser revertidos por diversos medios, o pueden mantenerse a nivel jurídico "formal" divorciado de la realidad socio-política.

Desde la perspectiva de las ciencias jurídicas, "la ciudadanía significa la condición jurídica de los individuos que determina, por un lado, su sumisión a la autoridad del Estado a que pertenecen, por otro, el libre ejercicio de los derechos y privilegios que la ley del Estado otorga, y el cumplimiento de las obligaciones impuestas por la ley de dicho Estado" (Hernández Rubio, 1975:397). Es decir, que la ciudadanía significa una relación entre las personas y el Estado que establece derechos y deberes entre ambos. La ciudadanía es un concepto de derecho público que implica responsabilidades del ciudadano como cumplir las leyes y pagar impuestos, y derechos como elegir al gobierno o ser electo, protección dentro y fuera del país, acceder a empleo público, asociación política y petición al gobierno.

En algunos casos, se han equiparado los conceptos de "ciudadanía" y "nacionalidad", ya que ambos aluden a una identidad, un territorio y un Estado compartidos por una sociedad. 
Sin embargo, jurídicamente se distingue la nacionalidad porque no implica necesariamente la ciudadanía. En caso de estados multinacionales, se puede compartir una ciudadanía pero tener distintas nacionalidades. El carácter activo de la ciudadanía es resaltado como un rasgo distintivo por Hernández Rubio, "La ciudadanía se diferencia de la nacionalidad en que ésta supone la mera cualidad de pertenecer a una nación, mientras que el concepto de ciudadanía implica la condición de ser miembro activo del Estado para tomar parte en sus funciones"(1975:399).

Legalmente, la ciudadanía puede adquirirse y perderse de diversas formas según el marco jurídico de cada país. En general, se adquiere al nacer en un territorio (ius solis) o por "herencia" de sus padres (ius sanguinis), también por voluntad en caso de residir en un país y solicitarlo al gobierno, o por matrimonio con un/a nacional. Se puede perder por renuncia expresa al aceptar otra ciudadanía en los casos que no se permite tener una doble o múltiple ciudadanía (Ramela, 1955:1038-40).

La globalización y los movimientos migratorios actuales han modificado el abordaje de la ciudadanía. La mayoría de los países ha abierto la vigencia de los derechos civiles y comerciales a personas de otros países, relegando exclusivamente a los ciudadanos el ejercicio de los derechos políticos. En los últimos años, los países del Norte han puesto restricciones fuertes -que implican un costoso y largo trámite-para el acceso de extranjeros a la ciudadanía, tales como cuotas por país/región, residencia legal por varios años, mayoría de edad, conocer la lengua, idoneidad cívica, capacidad económica para atender sus necesidades y/o empleo contratado (Castro, 2005).

Desde una perspectiva sociológica se destaca la teoría de Marshall (1997), quien plantea que la ciudadanía es un estatus socio-político que conlleva iguales derechos y deberes para sus miembros, y que se manifiesta en tres dimensiones:

- La "ciudadanía civil” significa el goce de derechos civiles como la libertad física y de expresión, de religión y de propiedad.

- La "ciudadanía política” implica el derecho de participar en partidos, elecciones y cargos estatales.

- La "ciudadanía social" abarca los derechos de educación, salud, habitación, empleo y seguridad social.

Marshall señala que existe una contradicción en las sociedades capitalistas contemporáneas entre el principio de igualdad de la ciudadanía y el principio de diferenciación del mercado, particularmente en la vigencia de la "ciudadanía social”, que el autor considera una condición necesaria para el ejercicio de las otras dos dimensiones. En este sentido, Bottomore (1992) distingue una "ciudadanía sustantiva" que implica tener las capacidades para ejercer los derechos de la "ciudadanía formal" o jurídica, y señala que la definición y vigencia de los derechos ciudadanos es un campo de lucha socio-política entre grupos sociales con intereses contrapuestos.

Esta distinción ha sido retomada desde un enfoque feminista, señalando que la igualdad formal de derechos que han alcanzado las mujeres en muchos países difícilmente se ejerce en la práctica por la desigualdad existente entre géneros, o mejor dicho por la subordinación 
del género femenino en distintos ámbitos sociales (familia, iglesia, empresa, partido, etc.) y la exclusión de oportunidades (educación, salud, etc.) que permitan desarrollar sus capacidades y sus derechos ciudadanos. La limitante clave de la participación ciudadana de las mujeres reside en la diferenciación entre un ámbito público asignados a los hombres donde se ejerce la política y la ciudadanía, y un ámbito privado o doméstico atribuido a las mujeres. Por esta razón, los movimientos feministas han planteado la ruptura de esta distinción patriarcal vía la politización de lo privado y el acceso equitativo de las mujeres al ámbito público (Aguilar, 1997:31-34). En el contexto latinoamericano, Ana García señala que "respecto a la ciudadanía formal, las diferencias entre mujeres y hombres se han reducido a su mínima expresión en los últimos cincuenta años. En cuanto a la ciudadanía sustantiva, la situación es claramente diferente" (García y Gomariz, 2001:206).

Coincidentemente, desde una perspectiva antropológica y con el auge de los movimientos indígenas, se ha señalado que muchos grupos étnicos se encuentran excluidos de las oportunidades y condiciones sustantivas para ejercer la ciudadanía formal. Así ha surgido un enfoque multicultural de la ciudadanía que enfatiza el respeto de la diversas identidades, normas y organizaciones propias de las diversas culturas existentes en un país y la necesidad de una "discriminación positiva" para que los grupos excluidos pueden acceder en igualdad de condiciones a los derechos ciudadanos (Bello, 2004). Como ha señalado Manuel Castells, "la concepción jurídico-política de la ciudadanía ha ido elaborando un estatus legal de ciudadanía igualitaria e indiferenciada, que en la práctica ha resultado ser excluyente de la pluralidad" (2004:37). Por el contrario, se argumenta que este enfoque multicultural lleva a la fragmentación de un estado-nación al enfatizar las identidades particulares sobre la identidad común como ciudadano, que ayuda a la cohesión socio-política de un país.

Las ciencias políticas nos recuerdan que el concepto de ciudadanía ha sido elaborado desde diversos marcos teóricos e ideológicos entre los que se destacan el liberalismo, el republicanismo y el comunitarismo. El enfoque liberal afirma el carácter individual de la ciudadanía, considerando que las personas son libres, soberanas, autónomas e iguales, y que los ciudadanos deben respetar los derechos de otras personas y cumplir con sus deberes cívicos acordados por el Estado. El enfoque republicano enfatiza el carácter ético y activo de la ciudadanía, argumentando la importancia de la participación política para el desarrollo de valores cívicos y la consolidación de un sistema político republicano. La concepción comunitarista plantea la preponderancia de los intereses colectivos sobre el interés individual, por tanto la ciudadanía tendría como finalidad la defensa del bien común y de los valores compartidos por una sociedad (Pérez Ledesma, 2004:20-25).

\section{La participación ciudadana}

El concepto de "participación" es definido como la "acción y efecto de participar", es decir se trata de "tomar parte" personalmente de una actividad o de un programa (temporal), $o$ "ser parte o miembro" de una organización o de una comunidad (permanente). Observamos que desde su definición encontramos variaciones significativas entre el participar coyunturalmente de una acción y el participar sistemáticamente de una institución social. Existen diferentes formas de involucrase en una actividad o emprendimiento, así como hay distintos ámbitos de la vida social donde cabe a las personas "tomar o ser parte". En el caso de la participación ciudadana nos referimos a un ámbito societal específico, denominado por 
algunos autores como "ámbito público" en tanto se abordan asuntos de interés común para los miembros de una sociedad, y por otros autores como "campo político", en la medida que interviene el Estado para normar ese asunto público que normalmente es objeto de disputa entre grupos sociales.

Para Bourdieu (1981), el "campo político" es un espacio de competencia por el poder. Lo describe de forma análoga al mercado económico: una relación de oferta de "productos políticos" como programas, conceptos, problemas, que realiza un grupo de profesionales de lo político, y una demanda de esos bienes por los ciudadanos que carecen de la posibilidad de producir políticamente. Desde un enfoque antropológico, Balandier (1992) considera que lo distintivo del campo político es la existencia de un poder definido como la capacidad de un(os) actor(es) social de dirigir a otros actores sociales. Sin embargo, señala la dificultad de diferenciar el campo político del económico y cultural.

Podemos considerar el "ámbito público o político" como una dimensión específica de la vida social donde los ciudadanos y las organizaciones compiten o concuerdan sobre las decisiones concernientes a los asuntos de interés común. Las fronteras del "ámbito público" han variado históricamente, así encontramos temas contemporáneos que hoy son objeto de discusión pública y de decisiones políticas, pero que décadas atrás no lo eran. Por ejemplo, la violencia intrafamiliar, las opciones sexuales, la contaminación ambiental, el salario mínimo, la subordinación de las mujeres, niños y etnias.

La ampliación del "ámbito público" ha sido fruto de las luchas de grupos excluidos por visibilizar sus demandas en un contexto de cambios culturales y educativos facilitados por la ampliación de las comunicaciones globales. Por el contrario, los sectores dominantes han contrarestado la ampliación del "ámbito público" en temas que afectan sus intereses de poder, tratando de relegarlos al "ámbito privado". Por ejemplo, al ámbito del mercado dominado por grandes empresas o al espacio de la familia dominada por el patriarca. Por estas razones, tanto el concepto teórico como el alcance real de la participación ciudadana, son una construcción histórica de los sujetos sociales en un contexto espacio-temporal determinado, dependiente de las condiciones existentes (sociales, económicas y políticas), de las capacidades de los sujetos (humanas y materiales) y de la correlación de fuerzas entre ellos.

Desde esta perspectiva del ámbito público, como espacio donde los ciudadanos y sus organizaciones debaten los asuntos de interés colectivo, se diluyen las distinciones que tratan de establecer algunos autores entre la "participación ciudadana" con la "participación social o comunitaria" o con la "participación política" (Cunill, 2003). Por el contrario, la identificación frecuente del "ámbito público o político" con la esfera de acción estatal, deja por fuera un sinnúmero de asuntos de interés común en los cuales los ciudadanos participan activamente, particularmente con el recorte de las capacidades y espacios de los Estados en América Latina, ocurrido en las últimas décadas. Por tanto, es discutible la reducción del concepto de participación ciudadana a las interrelaciones con el Estado.

Sin embargo, la mayoría de las definiciones de participación ciudadana, como señala Cunill, se enfocan en "aquel tipo de práctica social que supone una interacción expresa 
entre el Estado y actores de la sociedad civil" (2003:4). Esta relación del ciudadano con el Estado puede darse de forma individual u organizada, como aclara Mayorga señalando que la finalidad de la participación ciudadana es "para hacer valer sus derechos e influir en sus políticas y funcionamiento" (2000:21), lo cual implica la distribución más equitativa del poder y de los recursos básicos.

Desde la perspectiva de la incidencia en políticas públicas, la participación ciudadana cabe en todas las fases de su ciclo, desde el diagnóstico de la problemática, pasando por la elaboración de la política, la planificación e implementación de programas y proyectos, hasta el monitoreo y la evaluación de resultados e impacto. En regímenes democráticos, la elección y revocación de autoridades de gobierno se realiza mediante la participación ciudadana en el sufragio (universal y secreto) de distintos candidatos que presentan los partidos políticos en un proceso debidamente organizado y dirigido por un tribunal o instituto electoral imparcial y transparente.

Sin duda, este enfoque de la participación ciudadana ligado a las relaciones con el Estado resulta más sencillo heurísticamente para la investigación y para la promoción al acotar claramente el objeto de estudio, contrariamente a un enfoque más extenso a todo el ámbito público. En este sentido, Ortega Hegg define la participación ciudadana a nivel local como la "interrelación de la ciudadanía del municipio con su gobierno local, con el objetivo de incidir en su constitución vía las elecciones, exigir derechos, cumplir obligaciones, influenciar sus procesos decisorios y controlar su gestión... la participación ciudadana en un régimen democrático comienza con la participación electoral... No obstante, la participación e incidencia en las decisiones de forma directa es cada vez más un valor que se impone en la democracia actual" (2002).

Por su parte, la Red Nicaragüense por la Democracia y el Desarrollo Local entiende por participación ciudadana "el conjunto de prácticas de intervención directa de ciudadanas y ciudadanos, de forma individual y colectiva ante el Estado, con el fin de alcanzar la igualdad política y social que les permita influir de forma permanente en las decisiones públicas y realizar un escrutinio de la administración pública que contribuya tanto a su eficiencia y su eficacia como a su democratización, incluida la elección de las autoridades locales y nacionales" (¿cuál documento?). Esta definición contempla los distintos roles que pueden desempeñar los ciudadanos frente al Estado: elector, fiscalizador, contribuyente, asociado y proponente de políticas públicas. Para la Red Nicaragüense por la Democracia y el Desarrollo Local Local, la participación ciudadana apunta a democratizar el Estado, pero requiere de la vigencia de un Estado de Derecho que implica la independencia de los poderes, el sometimiento de todos los ciudadanos a las leyes y normas emanadas de poderes designados democráticamente, y el respeto a las libertades y derechos humanos. Las cualidades de una participación ciudadana efectiva e integral que promueve la Red son: informada, pluralista, autónoma, sistemática y vinculante (Red Nicaragüense por la Democracia y el Desarrollo Local, junio 2007).

La concepción de la Coordinadora Civil aporta nuevos elementos al definir la participación ciudadana como "el conjunto de prácticas que definen a una persona como miembro de pleno derecho (derechos y deberes) dentro de una sociedad. La ciudadanía implica normas 
jurídicas que otorgan la calidad de ciudadano/a; conciencia de ser parte de la comunidad política y de ser acreedor/a de los derechos; obligaciones a cargo de las instituciones públicas para responder a los compromisos de participación de los derechos conferidos" (Red Nicaragüense por la Democracia y el Desarrollo Local y Coordinador Civil, 2007). Es importante relevar las obligaciones que implica la ciudadanía para con sus semejantes (por ejemplo, el respeto a los derechos de los demás) y para con el Estado (pagar impuestos, cumplir leyes), que son la contracara de los derechos que tiene legalmente y cuyo cumplimiento puede exigir al Estado.

Por su parte, la "Ley de Participación Ciudadana” (475-2003) (Gobierno de la República de Nicaragua, 2003) la define así: "Es el proceso de involucramiento de actores sociales en forma individual o colectiva, con el objeto y finalidad de incidir y participar en la toma de decisiones, gestión y diseño de las políticas públicas en los diferentes niveles y modalidades de la administración del territorio nacional y las instituciones públicas con el propósito de lograr un desarrollo humano sostenible, en corresponsabilidad con el Estado". Según esta ley, la participación es un derecho de los ciudadanos que se caracteriza por ser voluntaria, universal, equitativa, solidaria y plural, y por otro lado, constituye una obligación del Estado hacerla efectiva.

Hay que señalar que este enfoque de participación ciudadana no se limita a los niveles tradicionales de brindar información sobre una política pública o una ley, tampoco la simple consulta de las opiniones de los ciudadanos, sino que se trata de una participación que alcanza el nivel decisorio en el diseño y la implementación de políticas públicas en conjunto con el gobierno. En su fundamentación, la ley señala que “...la gestión pública no puede ser concebida hoy en día sin la participación directa y permanente de la ciudadanía, pues esto constituye... a convertirlos... en protagonistas de los procesos de transformación de la sociedad nicaragüense..." (Gobierno de la República de Nicaragua, 2003).

\section{Condicionantes de la participación ciudadana}

Existen múltiples enfoques sobre los factores condicionantes de la participación ciudadana según los marcos teóricos, los estudios particulares o las experiencias políticas de los analistas. Una distinción básica entre dos concepciones ha sido planteada por Valles (2002:245-7):

- por un lado, un enfoque de cálculo racional según el cual los ciudadanos/as hacen una valoración de los costos y los beneficios que obtendrían antes de decidirse a participar,

- y por otro lado, un enfoque socio-cultural que enfatiza los valores y normas sociales que aprendió un ciudadano desde su niñez como los determinantes de su participación en una acción ciudadana.

En la Nicaragua actual podemos observar ambos tipos de condicionantes. Por ejemplo, en la adhesión de ciudadanos a los nuevos Consejos de Participación Ciudadana se pueden plantear varias hipótesis: por un lado, un cálculo de los beneficios que recibirá vía programas estatales o empleo público vs. los costos de tiempo y esfuerzo para ir a reuniones o celebraciones. También, puede haber un factor de identidad político-ideológica amamantada 
desde la tierna infancia en el seno de una familia sandinista y reforzada por la vinculación con medios de difusión y organizaciones afines. Queda planteado el interrogante: ¿el cálculo racional es necesariamente excluyente con el marco cultural o ambos factores pueden ser conjugados en distintas formas?

Diversos estudios han mostrado una correlación fuerte entre participación ciudadana y variables como:

- El género; en muchas sociedades el rol de la mujer está centrado en el ámbito doméstico mientras que el hombre se ocupa del ámbito público.

- $\quad$ El capital social; la participación solidaria en organizaciones civiles y redes sociales facilita la intervención ciudadana en asuntos de interés común (Wallace Salinas, 2002:20).

- El nivel escolar; una mayor educación facilita el acceso y análisis de información y desarrolla capacidades de expresión e intervención ciudadana (Dowse y Hughes, 1982:369-376).

La relevancia de la información y la educación como condicionantes de la participación ciudadana ha sido destacado por Dalton, quien ha identificado el factor llamado "movilización cognitiva" como un facilitador del crecimiento de la participación ciudadana tanto en cantidad de personas como en la sofisticación de los métodos usados: "La movilización cognitiva implica dos desarrollos separados, primero ha habido un descenso del costo de adquirir información política, segundo ha habido un aumento de la capacidad del ciudadano para procesar información. La movilización cognitiva significa que más ciudadanos ahora tienen recursos y habilidades necesarias para abordar el complejo mundo político y tomar sus propias decisiones" (Dalton, 1996:21).

Una categorización tradicional de los condicionantes de la participación ciudadana se vincula con la visión arquitectónica de la sociedad como una estructura compuesta por tres dimensiones o subsistemas interconectados -económico, político y cultural-en cada uno de los cuales pueden identificarse condiciones que facilitan la participación ciudadana (y su ausencia la obstaculiza):

- A nivel económico, la satisfacción de las necesidades materiales básicas, la ruptura de los lazos de dependencia y explotación, la existencia de medios de comunicación y transporte que faciliten los flujos informativos y las reuniones colectivas.

- A nivel político, el Estado de Derecho, la vigencia de derechos individuales y colectivos tales como la igualdad ante la ley, libertad de expresión, movilización y organización, la elección y revocación de dirigentes y su control por las bases.

- A nivel cultural, el acceso a información veraz y educación básica, el respeto a la diversidad cultural, el predominio de concepciones favorables a la participación, el sentimiento de integración social, y los valores de justicia, equidad y solidaridad. 
Hay que recordar que el ejercicio de la participación ciudadana está mediado por la cultura política predominante, incluyendo el nivel de conocimiento sobre los derechos y deberes. En este sentido, los grupos sociales hegemónicos tratan de mantener la pasividad de la ciudadanía y su aceptación de la exclusión social que padecen, mediante la difusión de un conjunto de representaciones y creencias que justifican el status quo como "natural". Por ejemplo, en América Latina diversos estudios han mostrado que la mayoría de los funcionarios públicos carecen de una concepción de ser un "servidor público" obligado a rendir cuentas e informar su gestión; por otro lado, los ciudadanos no tienen la costumbre de pedir cuentas e informes a los empleados públicos que manejan fondos originados en los aportes de los contribuyentes. Sin embargo, se observa en la región una creciente conciencia en los ciudadanos/as de sus derechos y sus responsabilidades gracias a la labor educativa que realiza un amplio sector de organizaciones civiles y los ejercicios de seguimiento de políticas públicas y de auditoría social de presupuestos municipales y nacionales, en muchos casos con apoyo de la cooperación externa.

\subsection{Fragmentación vs. globalización}

El reconocimiento a las distintas identidades culturales de un estado-nación, que implica muchas veces una autonomía relativa en un territorio culturalmente homogéneo (por ejemplo, regiones de Bélgica o España), ha sido señalado como una tendencia a la "fragmentación" de la ciudadanía. Frente a esta situación aparece un factor condicionante clave en el siglo XXI que destaca Castells (2004): el proceso de globalización que -contrariamente a la fragmentación- tiende a la trans-nacionalización de la ciudadanía, como son los espacios regionales con sistemas políticos consensuados (por ejemplo, la Unión Europea).

Sin embargo, la globalización ha limitado los derechos ciudadanos de carácter económico, social y cultural "dado que el proceso de globalización económica impone la ley de los grandes mercados financieros por encima de las decisiones y de los criterios sociales negociados democráticamente por los Estados, la consecuencia inmediata de esto se traduce, por ejemplo, en un retroceso en la protección social de los ciudadanos..."(Castells, 2004:44).

Una expresión de la globalización son las corrientes migratorias del Sur al Norte y entre polos económicos de un territorio en función de las inversiones transnacionales, que plantean nuevos retos al concepto de ciudadanía ya que esa creciente población requiere del reconocimiento de sus derechos civiles, sociales y económicos, y eventualmente de sus derechos políticos si opta por un proceso jurídico de nacionalización. Sin embargo, hay que reconocer dos situaciones muy distintas que señala Sojo (2002:125): "Los ciudadanos modelo de la globalización son los 'hiper-ciudadanos'... que transitan los flujos transnacionales de comercio, la información y el capital. Los demás quedan en una condición 'pre-ciudadana' que carece de los beneficios más elementales de la pertenencia ciudadana...”.

\subsection{Condiciones estructurales y coyunturales}

Desde una perspectiva histórica se pueden distinguir condiciones de "larga duración" que las sociedades han construido durante siglos a fin de responder a sus necesidades comunes de reproducción material, organización social y orientación de su acción. Se trata de 
elementos estructurales de lenta transformación por su "peso inercial", tales como el modo de producción, los sistemas políticos, las cosmovisiones religiosas y sus instituciones.

Por otro lado, existen las condiciones coyunturales que son un conjunto de acontecimientos de distinta índole (catástrofe natural, agresión colectiva, nueva autoridad o ley) que ocurren en un corto plazo y que afectan a la ciudadanía motivando su participación muchas veces con el apoyo de una organización y/o un líder carismático. Estos factores coyunturales son "aceleradores de la historia" que pueden provocar experiencias ciudadanas que facilitan la constitución de una identidad común de los individuos involucrados en torno a ciertos intereses percibidos como homogéneos, todo ello ligado al desarrollo de un compromiso con el cambio histórico (Serrano Caldera, 2001). Estos tres aspectos (experiencia, identidad, compromiso) facilitan el tránsito de una participación individual del ciudadano a una experiencia colectiva propia de un movimiento social que puede incidir con mayor efectividad en la transformación del status quo, sea el rechazo de una medida que afecta sus intereses o la aprobación de una política que responda a sus derechos (Serra Vázquez, 2003).

\section{Tipos y niveles de participación ciudadana}

En la literatura académica encontramos diversos criterios de clasificación de la participación ciudadana, denominados indistintamente "tipos", "formas" o "niveles". Este artículo menciona las categorías más relevantes para el estudio y para la promoción de la participación ciudadana en Nicaragua. Comenzamos con las categorías dicotómicas sencillas y luego abordamos tipologías complejas.

Formal, sustantiva, ejercida: la primera se refiere al reconocimiento jurídico de la participación ciudadana, mientras que la "sustantiva" apunta a la existencia de condiciones necesarias para poder implementarla. Sin embargo, pueden existir esas condiciones y los ciudadanos no participan. Por eso Maihold plantea la categoría de "ejercida" para referirse al uso activo de las condiciones materiales y formales para participar (Maihold y Córdoba, 2001). En otros términos se distingue el ámbito normativo y material de su práctica real. El primero es una condición necesaria pero no suficiente para una ciudadanía activa. Esta meta requiere, en primer lugar, de un marco jurídico que recoja los derechos de participación ciudadana en sus tres ámbitos (civil, político, socio-económico); en segundo lugar, de políticas públicas que brinden las condiciones sustantivas necesarias; y en tercer lugar, se trata de acortar la brecha entre dichas normas (que plantean un "deber ser") con la práctica concreta de la participación ciudadana a través de diversas medidas (información, educación, concertación, organización).

- Directa o representativa: La primera alude a la acción personal de un(os) ciudadanos(s) de gestión ante instituciones del Estado (por ejemplo, reclamo por servicios, elección de gobierno) y la segunda se refiere a una forma de participación indirecta en la gestión pública a través de representantes o delegados nombrados por los ciudadanos/as (por ejemplo, Comité de Desarrollo Municipal). Ya mencionamos que por razones demográficas y prácticas predominan en las sociedades modernas las formas representativas. La calidad de dicha representación depende de varios factores: la legitimidad de la elección del delegado, la consulta previa de los asuntos a gestionar o acuerdos a tomar con otros 
actores y a la información/rendición de cuentas del líder ante sus representados. La carencia de estas condiciones, observable tanto en organizaciones civiles como políticas en Nicaragua, resta legitimidad a la participación de líderes o delegados en asuntos públicos, quienes se habitúan a tomar acuerdos con otros actores sin consensuarlos con sus representados.

- Individual o colectiva: Estas categorías se asemejan a las anteriores pero tienen una diferencia: el primer caso se refiere a la participación de un solo individuo en la gestión pública de su interés particular, sea directamente o a través de un delegado (por ejemplo, solicitud, queja o propuesta). En cambio, el segundo caso alude a un grupo social o un colectivo de personas que participan de forma conjunta en la gestión de un interés común, sea directa o indirectamente. Obviamente, la superación de problemas sociales requiere de una participación colectiva y organizada, aunque hay individuos que prefieren buscar una solución personal, especialmente cuando tienen "contactos" con funcionarios o puertas traseras de acceso (por ejemplo, el soborno).

- Coyuntural o permanente: Considerando el lapso de tiempo de la participación ciudadana, se distingue una forma transitoria y puntual de participación (coyuntural) en asuntos inmediatos, y otra de carácter sostenido o permanente vinculada a organizaciones y estrategias de mediano o largo plazo. La solución de problemas complejos y la necesidad de incidir y monitorear la gestión pública requiere de una participación ciudadana permanente o al menos con la frecuencia suficiente para cumplir sus funciones con eficacia. Sin embargo, en coyunturas críticas donde están en juego intereses ciudadanos clave, se requiere de una participación ciudadana amplia y beligerante para defender sus derechos.

- Convencional e informal: La primera categoría se refiere a las formas de participación ciudadana que están enmarcadas en las vías legales y aceptadas de participación, mientras que las formas no convencionales o informales aluden a tipos de acción que van mas allá del marco jurídico según la capacidad y la creatividad de los/as ciudadanos/as. Estas últimas se observan cuando las vías convencionales han sido agotadas sin resultados para la ciudadanía o cuando el régimen político restringe las libertades básicas. En Nicaragua muchas veces los gobiernos no escuchan las demandas ciudadanas canalizadas por medios legales y pacíficos, hasta que el conflicto escala y explotan métodos violentos de lucha como cortes de rutas, quema de llantas y enfrentamientos con la Policía provocando heridos y muertos. Esta situación repetida provoca un descrédito de las formas convencionales de participación y una tendencia a usar métodos alternativos a pesar de sus riesgos y de la desaprobación de muchos ciudadanos.

- De arriba hacia abajo o viceversa: Esta categoría identifica la dirección de la iniciativa y organización de la participación ciudadana. El primer caso es el más común ya que se trata de una participación ciudadana promovida desde los altos funcionarios de gobierno, de partidos o de otras organizaciones, mientras que la segunda opción se refiere a un proceso de participación ciudadana que ha nacido desde la gente de "base", las comunidades y los grupos locales, y se va extendiendo en ámbitos sociales y territoriales 
más amplios a medida que genera consensos y acumula fuerzas. Esta clasificación se relaciona con los temas o asuntos que motivan la participación ciudadana. En el primer caso son cuestiones decididas a nivel central y que tratan de ser "inducidas" a nivel local, mientras que la segunda opción abarca temas propios y prioritarios de la población participante e implica que existe un nivel de autonomía de la ciudadanía y sus organizaciones de base. El reto sería planear un proceso participativo en doble vía que inicie en cualquiera de los dos extremos, pero que garantice el consenso en las decisiones.

- Según la geografía política donde ocurre la participación ciudadana se puede distinguir una tipología que comprende la participación en una escala que va desde el nivel micro: comunal y municipal, pasando por el ámbito departamental o regional, hasta alcanzar un espacio nacional, centroamericano, latinoamericano o global. Lógicamente, a mayor amplitud espacial se requiere una mayor fortaleza en la comunicación, coordinación y organización de los ciudadanos participantes para poder interlocutar con las instituciones políticas correspondientes.

- Información, consulta o decisión: Una clasificación muy utilizada. Se basa en las oportunidades que tienen los ciudadanos frente a las instituciones políticas. Un primer nivel es contar con la información sobre la política o acción pública que se ha aprobado, un segundo escalón es la consulta a los ciudadanos sobre decisiones públicas antes de ser implementadas (pero la decisión final queda en otras manos) y un tercer nivel, es la oportunidad de que los ciudadanos tengan voz y voto en las decisiones que se toman sobre asuntos públicos, es decir que sus propuestas (fundamentadas, legitimadas y factibles) sean "vinculantes" u obligatorias para los funcionarios públicos como plantea la Red Nicaragüense por la Democracia y el Desarrollo Local. A este último nivel debemos aspirar para contar con una ciudadanía activa y propositiva, tal como está consignado en la Ley de Participación Ciudadana (475-2003).

- Retórica, obligada o consciente: Esta clasificación enfoca el grado de voluntariedad y conocimiento de los ciudadanos participantes en alguna acción cívica. El primer caso (retórica) alude a un nivel verbal de participación que se queda a nivel discursivo sin actividades prácticas, el segundo caso significa que existe una participación real de los ciudadanos pero condicionada por una obligación o incentivo material que ofrecen los "promotores", y el tercer nivel ocurre cuando los/as ciudadanos/as están concientes de la situación, aprueban las acciones propuestas y participan voluntariamente por convicción. Sin duda que este último sería la meta en un proceso de construcción de una ciudadanía activa, autónoma y propositiva.

- Ciclo de políticas: En el ámbito de la formulación y ejecución de políticas públicas, programas deinversión y proyectos de desarrollo, se distinguenlos niveles departicipación ciudadana según las etapas del ciclo de estos procesos: diagnóstico, planificación, ejecución, monitoreo y evaluación. Generalmente, la participación ciudadana se reduce a brindar información en la primera etapa del diagnóstico. Sin embargo, es recomendable una participación ciudadana sistemática en todas sus etapas, particularmente en el monitoreo, evaluación y retroalimentación de su implementación. 
- Áreas de participación: Algunos autores clasifican la participación ciudadana conforme las áreas o temáticas que abordan. Así, Wallace (2002) distingue tres áreas básicas: a) formación de políticas públicas (facilitando la intervención de intereses ciudadanos); b) acción legislativa (iniciativa de ley, referéndum, revocación del mandato de autoridades electas); c) Prestación de servicios públicos (transferencia o cogestión).

- Según los resultados de la participación ciudadana se pueden clasificar en experiencias que producen resultados inmediatos y visibles, a diferencia de otros procesos cuyos resultados son a mediano/largo plazo o de carácter no tangible (por ejemplo, conocimientos). En este último caso es más difícil que el primero mantener motivada la participación ciudadana, el reto estaría en articular ambos. Otro enfoque de los resultados es ver si son satisfactorios para los ciudadanos, o no lo son por su baja calidad o porque se limitan a un sector de la población, y por tanto se desmotiva la participación ciudadana.

Una de las clasificaciones clásicas de participación ciudadana fue elaborada por Arnestein (1969) a partir de la evaluación de programas de participación ciudadana de población pobre afrodescendiente en nuevas urbanizaciones de Estados Unidos en las que encontró una variedad de situaciones que resume en siete niveles, desde los casos más débiles de participación ciudadana hasta los más consolidados:

1 Manipulación: se forman comités consultivos donde los ciudadanos son persuadidos por los funcionarios sobre la decisión a tomar.

2 Terapia: los ciudadanos participan en sesiones de "educación" y cambio de valores y actitudes para que se integren mejor a la sociedad.

3 Información: se brinda a los ciudadanos información sobre sus derechos, deberes y opciones, aunque pocas veces es una comunicación de doble vía con los tomadores de decisión.

4 Aplacamiento: se permite la participación de representantes de los ciudadanos en comités o juntas donde se acuerdan los planes y acciones, pueden expresar sus opiniones pero están en minoría.

5 Concertación: los ciudadanos y sus organizaciones participan como socios con las instituciones ejecutoras del programa, las decisiones se toman de forma conjunta entre todos.

6 Poder delegado: los ciudadanos tienen mayoría de votos en los consejos o juntas directivas del programa, o tienen poder de veto de las decisiones que tomen las instituciones ejecutoras.

7 Control ciudadano: los ciudadanos toman las decisiones en la formulación del programa y manejan su administración, pudiendo negociar acuerdos con instituciones estatales y otras.

Desde una conceptualizacion de la participación ciudadana a partir de la categoría filosófica y sociológica de la "praxis", se la ha definido como una actividad práctica y reflexiva de reproducción y transformación de la realidad social, al mismo tiempo que desarrolla la identidad colectiva y la capacidad de autogestión del actor o sujeto social. La participación ciudadana se compone de elementos "objetivos" como las actividades y sus resultados 
(leyes, políticas, servicios) y elementos "subjetivos" como los conocimientos, sentimientos, valores e intenciones. Ambos componentes están interrelacionados y en procesos dinámicos de cambio (Serra Vázquez, 2003).

Como se muestra en el Cuadro 1, en base a estas premisas se puede construir una tipología de participación ciudadana según el grado de desarrollo de sus aspectos objetivos y subjetivos, el nivel de interrelación y el tipo de práctica.

Cuadro 1. Tipología de participación ciudadana

\section{Participación espontánea}

Se caracteriza por una débil interrelación entre lo ideal y lo material, una mínima elaboración subjetiva (fines, conocimientos, valores) y una actividad práctica errática.

\section{Participación reflexiva}

Se define por tener una interrelación fuerte entre lo ideal y lo material, una máxima elaboración subjetiva y una práctica coherente con el discurso.

\section{Praxis creativa}

Se define por una actividad de reproducción del sistema político existente, la actividad subjetiva es mínima en relación a la práctica, aceptándose acríticamente el status quo.
Se define por la producción de nuevos resultados con una actividad subjetiva dinámica en íntima relación con la actividad práctica, resultando en un proceso de autoconstrucción integral del sujeto colectivo e individual.

Desde la sociología de la infancia, diversos autores han propuestos tipologías de participación de la niñez y adolescencia, un sector de la ciudadanía generalmente subestimado o excluido por los adultos tanto en el ámbito privado como en el público. En la participación ciudadana de niños y adolescentes influyen factores específicos tales como la apertura al diálogo de padres y adultos cercanos, la seguridad del entorno social, el desarrollo de las capacidades del propio niño/a y otras condiciones básicas como salud, buena alimentación y atención con cariño.

Para Hart (1992), una participación efectiva de los/as niños/as supone al menos una interacción de aprendizaje social entre adultos y niños/as donde éstos son informados y consultados previo a las decisiones y acciones a tomar. Por fuera quedan otras modalidades muy frecuentes como la manipulación, la presencia simbólica y la ejecución de órdenes de los/as adultos. El siguiente es un cuadro comparativo de las tipologías más conocidas actualmente sobre la niñez. 
Cuadro 2. Tipologías de participación de la niñez y adolescencia

\begin{tabular}{|c|c|c|c|}
\hline Hart & Goetz & Unicef & Banco Mundial \\
\hline $\begin{array}{l}\text { Iniciativa niños/as, } \\
\text { decisiones comparti- } \\
\text { das con adultos }\end{array}$ & Auto-movilización & $\begin{array}{l}\text { Análisis de situa- } \\
\text { ciones y tomando } \\
\text { opciones }\end{array}$ & \\
\hline $\begin{array}{l}\text { Iniciativa y dirección } \\
\text { de niños/as }\end{array}$ & & $\begin{array}{l}\text { Iniciando ideas y pro- } \\
\text { puestas y proyectos }\end{array}$ & Creación social \\
\hline \multirow[t]{3}{*}{$\begin{array}{l}\text { Inicio por adultos, } \\
\text { compartido con niños/ } \\
\text { as }\end{array}$} & $\begin{array}{l}\text { Participación } \\
\text { interactiva }\end{array}$ & $\begin{array}{l}\text { Informado y consul- } \\
\text { tado en la toma de } \\
\text { decisiones }\end{array}$ & $\begin{array}{l}\text { Aprendizaje } \\
\text { social }\end{array}$ \\
\hline & $\begin{array}{l}\text { Participación } \\
\text { funcional }\end{array}$ & $\begin{array}{l}\text { Participación en ac- } \\
\text { tividades y procesos }\end{array}$ & \\
\hline & $\begin{array}{l}\text { Participación por } \\
\text { incentivos mate- } \\
\text { riales }\end{array}$ & & \\
\hline $\begin{array}{l}\text { Consultado e infor- } \\
\text { mado }\end{array}$ & $\begin{array}{l}\text { Participación vía } \\
\text { consulta a niños/ } \\
\text { as }\end{array}$ & $\begin{array}{l}\text { Elaboración y ex- } \\
\text { presión de opiniones } \\
\text { e ideas }\end{array}$ & Consulta \\
\hline $\begin{array}{l}\text { Acción ordenada con } \\
\text { información }\end{array}$ & $\begin{array}{l}\text { Participación en } \\
\text { brindar infor- } \\
\text { mación }\end{array}$ & $\begin{array}{l}\text { Buscando infor- } \\
\text { mación }\end{array}$ & Escuchando \\
\hline $\begin{array}{l}\text { Participación sim- } \\
\text { bólica }\end{array}$ & & & $\begin{array}{l}\text { Enfoque experto } \\
\text { externo }\end{array}$ \\
\hline \multicolumn{4}{|l|}{ Presencia decorativa } \\
\hline Manipulación & & & \\
\hline
\end{tabular}

Fuente: Lieten (2003:8)

En el Cuadro 2 observamos escalas de participación de la niñez que retoman muchas de las categorías que presentamos anteriormente para adultos. Se presentan diferencias según los enfoques de los autores, pero contienen elementos básicos en común en esa graduación de creciente participación: un nivel básico de información seguido de un nivel de consulta de los adultos en decisiones que les atañen para avanzar a un nivel de codecision y cogestión entre adultos y niños/as, y llegar al utópico nivel de autogestión infantil.

En relación a la participación ciudadana a nivel local, existe en Centroamérica una valiosa propuesta elaborada por Casasfranco y Patiño (2001:295-298). Los autores desglosan el tema 
de la participación ciudadana en cuatro dimensiones: las formas, los espacios, la amplitud y la incidencia de la participación ciudadana. En cada dimensión identifican una gradación de niveles que mostramos en el Cuadro 3:

Cuadro 3. Tipología de participación ciudadana a nivel local

\begin{tabular}{|c|c|c|}
\hline Dimensión & $\begin{array}{l}\text { Posiciones } \\
\text { extremas }\end{array}$ & Niveles de participación \\
\hline Formas & $\begin{array}{l}\text { De la utilización por parte } \\
\text { de grupos de poder...al } \\
\text { control ciudadano }\end{array}$ & $\begin{array}{l}\text { 1. Consulta puntual y a posteriori } \\
\text { 2. Consulta organizada a la ciudadanía } \\
\text { 3. Concertación institucionalizada } \\
\text { 4. Fiscalización y contraloría social } \\
\text { 5. Procesos autogestionarios }\end{array}$ \\
\hline Espacios & $\begin{array}{l}\text { Del centralismo al autogo- } \\
\text { bierno local }\end{array}$ & $\begin{array}{l}\text { 1. Procesos centralizados por gobierno } \\
\text { nacional } \\
\text { 2. Desconcentración a municipios } \\
\text { 3. Mezcla de descentralización y descon- } \\
\text { centración } \\
\text { 4. Descentralización con autonomía local } \\
\text { en construcción } \\
\text { 5. Descentralización con alto nivel de } \\
\text { autonomía local }\end{array}$ \\
\hline Amplitud & $\begin{array}{l}\text { De la exclusión } \\
\text { a la inclusión }\end{array}$ & $\begin{array}{l}\text { 1. Procesos limitados a unos pocos selec- } \\
\text { cionados } \\
\text { 2. Procesos con representantes de grupos } \\
\text { organizados } \\
\text { 3. Procesos combinados: asambleas y } \\
\text { representantes } \\
\text { 4. Procesos con amplia participación en } \\
\text { todo el ciclo }\end{array}$ \\
\hline Incidencia & $\begin{array}{l}\text { De lo asistencial } \\
\text { a lo estructural }\end{array}$ & $\begin{array}{l}\text { 1. Alivio de efectos de una problemática } \\
\text { 2. Compensación de efectos de políticas } \\
\text { publicas } \\
\text { 3. Procesos sectoriales de reforma } \\
\text { 4. Procesos integrales de reforma } \\
\text { 5. Procesos integrales de cambio } \\
\text { estructural }\end{array}$ \\
\hline
\end{tabular}

Esta tipología retoma algunas de las categorías antes mencionadas de forma dicotómica -por ejemplo, formas y amplitud-precisando una diversidad de niveles que facilitan su operacionalización en investigaciones o intervenciones sobre la participación ciudadana. 
Los autores incorporan un elemento condicionante clave de la participación ciudadana local, y es contar con un sistema político que permita un nivel suficiente de descentralización y de autonomía local, complementada con capacidad financiera y de gestión. También estos autores adicionan a la temática el debate sobre actividades asistencialistas, reformistas o de cambio estructural, presuponiendo que el cambio del sistema político y socio-económico es necesario para una vigencia de los derechos ciudadanos en todas sus dimensiones.

Por último, desde la perspectiva del proceso de transformación de una participación ciudadana individual a una grupal que puede adquirir la categoría de movimiento social, se ha propuesto la siguiente tipología de niveles de evolución y consolidación de la participación ciudadana (Serra Vázquez, 2003):

- "Dispersión individual": En esta situación, los miembros de un sector social viven bajo iguales condiciones objetivas sin conciencia de una identidad común, fraccionados por múltiples divisiones subjetivas que buscan una salida personal vía clientelismo. Hay una aceptación pasiva del status quo -salvo protestas individuales efímeras contra el sistema dominante- y de la emisión del voto en elecciones.

- "Movimiento de protesta": En este caso aparece una primera conciencia de intereses ciudadanos grupales frente a "enemigos" comunes que se expresa en movimientos contestatarios de corta duración y de carácter inorgánico y parcial, y donde la personalidad carismática de un líder cobra papel motivador fundamental.

- “Actor social institucionalizado": En esta situación existe una conciencia de identidad colectiva que se expresa en la participación activa de gran parte de la ciudadanía, en forma organizada y permanente, en torno a un proyecto social propio, aunque estableciendo alianzas con otros actores y utilizando mecanismos legales de incidencia política.

- "Movimiento democrático solidario": En este caso los ciudadanos organizados no sólo luchan por sus objetivos sectoriales sino que los trascienden al colaborar con otros actores sociales en la lucha por un proyecto liberador integral. A nivel interno, el movimiento actúa de forma organizada y permanente, basado en la democracia, la comunicación y la transparencia.

\section{Conclusiones}

Hemos comprobado que existe una diversidad de acepciones y enfoques sobre la participación ciudadana. Esta ambigüedad del concepto dificulta su identificación y estudio, así como la formulación de políticas y proyectos para la “construcción deciudadanía” yla democratización de Nicaragua. Sin embargo, la relevancia del tema nos obliga a tratar de definir con rigor el concepto (y las prácticas que representa) de participación ciudadana desde una perspectiva multidisciplinaria y plantear los distintos niveles o tipos de participación posibles.

En América Latina, el tema de la participación ciudadana ha concitado en las últimas décadas el interés de políticos, académicos y líderes civiles, dado que constituye un 
elemento clave para la democratización del sistema político y para un desarrollo sostenible e inclusivo. Todos/as reconocen que la participación ciudadana en los asuntos públicos que afectan sus intereses individuales o sociales es un componente clave de una "gobernabilidad democrática”. Una participación oportuna otorga a las políticas públicas que han sido consensuadas con la ciudadanía la oportunidad de enriquecerse con sus aportes, además de dotarlas de la legitimidad que facilita su validez y su cumplimiento efectivo.

Desde una perspectiva histórica, vemos que la ampliación del concepto y la práctica de "ciudadanía" ha sido un largo proceso histórico -impulsado por los grupos sociales excluidos de las decisiones políticas- que continúa hasta el presente siglo. Paralelamente, con este proceso histórico de ampliación de la ciudadanía encontramos el desarrollo de la democracia como sistema político de la mayoría de los Estados actuales. Hoy día la participación ciudadana es un derecho universal que ha sido reconocido en acuerdos internacionales e incluido en los marcos jurídicos nacionales. Sin embargo se observa una brecha considerable entre el "deber ser" jurídico y el ejercicio real de estos derechos ciudadanos en muchas naciones.

El concepto mas extendido de "ciudadanía” proviene de las ciencias jurídicas, enfocándola como una relación legal entre las personas y el Estado que establece derechos y deberes entre ambos. Por tanto, la definición generalmente aceptada de "participación ciudadana" se refiere a todas aquellas prácticas de interacción entre los actores de la sociedad civil y el Estado. Es decir que el concepto alude a las acciones de intervención de ciudadanas y ciudadanos de forma individual y colectiva, ante las instituciones del Estado, sea como elector, fiscalizador, contribuyente, asociado o proponente de políticas públicas.

Un concepto sociológico de ciudadanía lo planteó Marshall (1997), quien distingue tres dimensiones: la "ciudadanía civil" que significa el goce de derechos civiles, la "ciudadanía política" que implica el derecho de participar en elecciones, y la "ciudadanía social" que abarca los derechos de educación, salud, habitación, empleo y seguridad social. La dimensión social ha sido ampliada gracias al aporte del movimiento feminista e indígena, así ha surgido un enfoque multicultural de la ciudadanía que enfatiza el respeto de las diversas culturas existentes en un país y que toma en cuenta las desigualdades de género para abogar por políticas que permitan a los grupos excluidos gozar de los derechos ciudadanos con equidad.

De esta forma se ha expandido y profundizado el concepto de "participación ciudadana" a las distintas dimensiones sociales antes señaladas. En otros términos, se trata de la participación de los ciudadanos/as en asuntos considerados de interés común o del "ámbito público" -categoría histórica definida en cada contexto según la correlación de fuerzas. En definitiva, tanto el concepto teórico como el alcance real de la participación ciudadana son una construcción histórica de los sujetos sociales en un contexto espacio-temporal determinado, dependiente de las condiciones existentes (sociales, económicas y políticas) y de las capacidades de los sujetos (humanas y materiales).

Hemos identificado los múltiples condicionantes que inciden en la posibilidad y la calidad de la participación ciudadana -tanto estructurales como coyunturales- y en las dimensiones 
política, económica y cultural. Se puede señalar que estas condiciones multidimensionales que posibilitan la participación ciudadana son a la vez resultado dialéctico de una participación efectiva acumulada por los/as ciudadanas en defensa y ampliación de sus derechos civiles, políticos y socio-culturales.

En particular, hemos identificado el proceso de globalización dirigido por las compañías transnacionales con el apoyo de la potencia hegemónica y sus organismos multilaterales que ha afectado los derechos socio-económicos de los ciudadanos pobres ("pre-ciudadanos") tanto en sus propios países (por ejemplo, las zonas francas) como al migrar a otros países en busca de empleo. Por otro lado, ha generado una "hiper-ciudadanía" para una clase minoritaria que se beneficia de y promueve este tipo de globalización excluyente.

Finalmente, hemos presentado un conjunto de clasificaciones de la participación ciudadana con el fin de poder identificar sus formas y niveles en Nicaragua, y también de plantear las metas para la promoción de una participación ciudadana integral. He aquí el reto de construir una participación ciudadana que alcance el nivel de decisión en políticas públicas, que existan condiciones jurídicas y materiales para su ejercicio por todos/as, que combine formas directas y representativas, que sea conciente, voluntaria y sistemática. Un primer paso sería la identificación y análisis de los factores que obstaculizan este proceso de construcción de ciudadanía para en un segundo momento plantear y consensuar medidas para superar esas limitantes y aprovechar las valiosas capacidades que tiene la ciudadanía nicaragüense y sus organizaciones civiles.

\section{Agradecimientos}

Agradezco a la Red Nicaragüense por la Democracia y el Desarrollo Local por su apoyo para la elaboración de este artículo como aporte al Observatorio Municipal de Participación Ciudadana.

\section{Referencias bibliográficas}

AGUILAR, A. (1997) Movimiento de mujeres en Centroamérica. Managua: Centro Editorial Mujer.

AQUIN, N. (2003) Ensayos sobre ciudadanía. Buenos Aires: Ed. Espacio.

ARNSTEIN, S. R. (1969) "A Ladder of Citizen Participation", AIP Journal, julio: 216-224.

BALANDIER, G. (1992) Antropologie Politique. Paris: PUF.

BELLO, A. (2004) Etnicidad y ciudadanía en América Latina. Santiago de Chile: CEPAL.

BOTTOMORE, T. (1992) Citizen and Social Class, Forty Years On. London: Pluto Press.

BOURDIEU, P. (1981) "La representation politique: elements pour une theorie du champ politique", Actes de Recherche en Sciencies Sociales, No.36-37.

CASASFRANCO, M. V. \& PATIÑO, M. F. (2001) "Participación ciudadana en el nivel local en Centroamérica: tendencias actuales y perspectivas”, en Córdoba, R. M. et al. (2001) Pasos a una Nueva Convivencia Democrática en Centroamérica. San Salvador: FUNDAUNGO. 
CASTELLS, M. (2004) “Globalización, ciudadanía y derechos humanos”, en Romeo, L. Teoría Política: Estado y Sociedad Civil, Compendio de Lecturas, Maestría en Ciencias Sociales, Managua: UCA.

CASTRO, H. M. (2005) Panorama de la ciudadanía, Cuaderno de Investigación N². Paris: FIUC.

CUNILL GRAU, N. (2003) "Los elementos básicos de la participación ciudadana” en Participación ciudadana y desarrollo local en Centroamérica. San Salvador: FUNDAUNGO.

DALTON, J. R. (1996) Citizen Politics: Public Opinion and Political Parties in Advanced Western Democracies. New Jersey: Chatham.

DICCIONARIO DE LA REAL ACADEMIA ESPAÑOLA, $22^{\circ}$ Edición, Disponible en:http://www. rae.es. Consultado: julio de 2008.

DOWSE, E.R. \& HUGHES, J.A. (1982) Sociología política, Madrid: Alianza.

GARCÍA, A. I. \& GOMARIZ, E. (2001) "Género y ciudadanía en Centroamérica”, en Córdoba R. et al. (2001) Pasos a una Nueva Convivencia Democrática en Centroamérica. San Salvador: FUNDAUNGO.

GOBIERNO DE LA REPÚBLICA DE NICARAGUA (2003) Ley de Participación Ciudadana $\mathrm{N}^{\circ} 475$, Managua.

HART, R. A. (1992) Children's Participation: From Tokenism to Citizenship. UNICEF.

HENGSTENBERG, P.; KOHUT, K. \& MAINHOLD, G. (eds) (1999) Sociedad Civil en América Latina: representación de intereses y gobernabilidad. Caracas: Nueva Sociedad.

HERNÁNDEZ RUBIO, J. M. (1975) Diccionario de Ciencias Sociales, Madrid: UNESCOIEP.

LIETEN, G. K. (2003) Participation: the Case of Children, Amsterdam: IREWOC.

MAIHOLD, G. \& CÓRDOBA, M. R. (2001), "Democracia y ciudadanía en Centroamérica” en Pasos hacia una nueva convivencia: democracia y participación en Centroamérica. San Salvador: FUNDAUNGO.

MARSHALL, T. H. (1997) Ciudadanía y clase social. Madrid: Alianza.

MAYORGA, J. (2000) La participación ciudadana en Nicaragua. Managua: Fundación Nueva Generación y Fundación K. Adenauer.

ONU (1948) Declaración Universal de los Derechos Humanos. Asamblea General de las Naciones Unidas No. 217 A.

ORTEGA HEGG, M. (2002) Construyendo la participación ciudadana en Centroamérica. Experiencias y tendencias regionales de participación ciudadana en la gestión local. Managua: CASC-UCA.

PÉREZ LEDESMA, M. (2004) "Ciudadanía y Democracia”, en Romeo L. Teoría Política: Estado y Sociedad Civil, Compendio de Lecturas, Maestría en Ciencias Sociales, Managua: UCA.

RAMELA, P. A. (1955) Enciclopedia Jurídica Omega, Tomo II, Buenos Aires: Driskill.

RED NICARAGÜENSE POR LA DEMOCRACIA Y EL DESARROLLO LOCAL (junio de 2007) La participación ciudadana que queremos. Managua.

REDNICARAGÜENSEPORLADEMOCRACIAYELDESARROLLOLOCALYCOORDINADORA CIVIL (CCER-CODA) (2007) Sistema de participación ciudadana para la incidencia en políticas públicas, Managua.

SERRA VÁZQUEZ, L. (2003) “Participación política y movimientos sociales”, Encuentro No. 64:18-37. Managua: UCA Publicaciones. 
SERRANO CALDERA, A. (2001) La democracia y sus desafíos en Nicaragua, Managua: CIELAC-UPOLI.

SOJO, C. (2002) "La noción de ciudadanía en el debate latinoamericano". Revista de la CEPAL, N ${ }^{\circ} 76$, abril:25-38.

VALLES, J. (2002) Ciencia Política: una introducción. Barcelona: Ariel.

WALLACE SALINAS, M. G. (2002) Participación ciudadana y su importancia para la transparencia en la gestión del gobierno municipal. Managua: Centro de Derechos Constitucionales. 